\title{
Merely asking the customer to recommend has an impact on word-of-mouth activity
}

Mattsson, Jan; Söderlund, Magnus

Published in:

Journal of Retailing and Consumer Services

DOI:

10.1016/j.jretconser.2015.07.009

Publication date:

2015

Document Version

Peer reviewed version

Citation for published version (APA):

Mattsson, J., \& Söderlund, M. (2015). Merely asking the customer to recommend has an impact on word-ofmouth activity. Journal of Retailing and Consumer Services, 27, 80-89.

https://doi.org/10.1016/j.jretconser.2015.07.009

\section{General rights}

Copyright and moral rights for the publications made accessible in the public portal are retained by the authors and/or other copyright owners and it is a condition of accessing publications that users recognise and abide by the legal requirements associated with these rights.

- Users may download and print one copy of any publication from the public portal for the purpose of private study or research.

- You may not further distribute the material or use it for any profit-making activity or commercial gain.

- You may freely distribute the URL identifying the publication in the public portal.

\section{Take down policy}

If you believe that this document breaches copyright please contact rucforsk@kb.dk providing details, and we will remove access to the work immediately and investigate your claim. 


\section{Merely asking the customer to recommend has an impact on word-of-mouth activity}

Both researchers and practitioners believe that word-of-mouth (WOM) is producing benefits for the firm. Typically, it is assumed that the receiver would find WOM particularly important and subject to less resistance than marketer-generated messages (Cheung et al, 2007; Mangold et al, 1999; Meuter et al, 2013; Schellekens et al, 2010; Sweeney et al, 2014; Söderlund and Rosengren, 2007; Trusov et al, 2009; Wien and Olsen, 2014). Therefore, WOM transmission, it is argued, is positively associated with sales growth (Reichheld, 2003). WOM is also assumed to reduce the firm's marketing expenses when existing customers who transmit WOM take on a marketing role, and thus several authors have argued that WOM is linked to the firm's profitability (e.g., Kumar et al, 2007). In addition, it has been noted that WOM is increasingly important in a situation in which communication through traditional media appears to be losing effectiveness (Sweeney et al, 2012; Trusov et al, 2009) and when social media has made WOM more rapid and pervasive (Wien and Olsen, 2014).

Given positive consequences of WOM, the antecedents of WOM become interesting particularly if they can be influenced by firms' activities. Several antecedents have received attention over the years. An early attempt to suggest specific activities to encourage the customer to transmit WOM is represented by Dichter (1966). The focus in subsequent research, however, has shifted towards general evaluation variables, which have been shown to be positively associated with WOM. Examples are customer satisfaction (Anderson, 1998; Ranaweera and Prabhu, 2003; Sweeney et al, 2012; Westbrook, 1987), perceived service quality (Danaher and Rust, 1996; Hartline and Jones, 1996), and perceived value (Sweeney and Soutar, 2001; Sweeney et al, 2012). Antecedents in terms of trust (Gremler et al., 2001), perceived novelty (Bone, 1992), affective commitment (Fullerton, 2005), and relationship commitment (Brown et al., 2005) have also been examined. In addition, individual characteristics, such as the sender's individualism (Wien and Olsen, 2014) and the sender's need to impress others, to help others, and to reduce cognitive dissonance (cf. Blackwell et al., 2001; Gelb and Johnson, 1995) have been examined as possible antecedents of WOM. Antecedents of these types may indeed be useful to boost WOM if they are parts of a larger 
conceptual network of (controllable) variables. For example, given a theory that states that the specific activity $\mathrm{X}$ produces more satisfaction, firms may decide to increase the frequency of $\mathrm{X}$ to increase satisfaction and thus obtain more WOM as an end product.

Direct influence attempts are also possible for marketers interested in boosting WOM activity, particularly in terms of so-called referral reward programs (a.k.a. "recommend-a-friendprograms"). Such programs have indeed become ubiquitous (Ryu and Feick, 2007; Verlegh et al, 2013; Xiao et al, 2011). Empirical research shows that they may encourage existing customers to provide WOM to friends, particularly when the customer is highly satisfied (Wirtz and Chew, 2002), when the recommended brand is weak, and when the transmitterreceiver relation represents a weak personal tie (Ryu and Feick, 2007). Such findings have also generated research regarding the design of referral reward programs in terms of, for example, if the transmitter, the receiver, or both of them should receive rewards. However, rewarding customers for WOM may backfire. In general, if the transmitter is viewed as a communicator - and if this communicator is seen as motivated by commercial interests - the message is likely to be met with resistance (Friestad and Wright, 1994). Thus, and in the specific case of WOM communication, if receivers of WOM become aware of the reward aspect, the trustworthiness aspect of WOM may be compromised (Tuk et al, 2009). That is to say, the effectiveness of WOM is likely to be reduced if the receiver believes that ulterior motives are involved (Verlegh et al, 2013). In addition, the reward aspect may also have a negative impact on the transmitter; if the transmitter feels that $\mathrm{s} /$ he has "sold" his/her recommendation, this may produce negative self-image reactions (Ryu and Feick, 2007).

What, then, if there is a simpler and more cost-efficient way to encourage WOM than referral rewards? The most straightforward way would be to ask the customer to engage in WOM. That is to say, merely requesting the customer to recommend an offer, without any reward system in place, costs very little. Yet would this work? Research in a related area, crossselling attempts, suggests that it may work, because simply asking the customer (who has already decided to purchase an item) if s/he also would consider buying an additional item has been shown to be a very cost-efficient practice to influence customer behavior and thus to increase sales (Söderlund, 2013). At the same time, a WOM request may be seen as an irritating and annoying tactic in the same way as intrusive advertising (cf. Edwards et al, 2002). However, so far, and to the best of our knowledge, the mere request approach has not been assessed in a WOM context. 
The purpose of this paper, then, is to explore empirically if merely requesting the customer within the frame of conversations in a service encounter - to recommend an offer would influence the customer's WOM activities. Two separate empirical studies were conducted to explore the issue.

\section{THEORETICAL FRAMEWORK}

The specific issue we focus on here is thus if merely requesting a customer to engage in WOM transmission would have an impact on the customer's subsequent WOM activities. Some theoretical arguments suggest a positive impact, yet arguments implying a negative impact exist, too. Such arguments are reviewed in the following sections.

Question-behavior effect studies

Several studies have shown that merely asking a question about behavior can influence subsequent behavior related to the question (Chandon et al, 2005; Sprott et al, 2006; Williams et al, 2006). One general label for this phenomenon is "the question-behavior effect" (Sprott et al, 2006). Most of the research in this area has dealt with questionnaire items, particularly intentions questions (e.g., "How likely is it that you will do X?") and self-prediction questions (e.g., "Do you predict that you will do X?"), and several studies show that respondents' exposure to such items makes behavior related to the questions more likely to be carried out (Chandon et al, 2005; Williams et al, 2006).

With regard to intention questions, one explanation is that when asked about intentions, preexisting intentions become more accessible in memory (and non-existing intentions may be formed), and this leads to increased strength in respondents' intentions compared to when no intention question is asked (Chandon et al, 2005). In the next step, and given the influence of intentions on behavior, behavior is expected to be affected. Alternatively, the mere asking about intentions may signal that someone cares about the respondent's views, which has a positive charge that may carry over to attitudes related to performing the behavior (ibid.). In both cases, actually performing the behavior would lead to a higher level of intentionbehavior consistency (and a high level of consistency is assumed to be particularly desirable, 
cf. Cialdini, 1987). Other researchers have stressed the possibility that an intention question may increase accessibility to existing attitudes toward a target, and given that those attitudes are positive it is likely that behavior towards the target follows (Sprott et al, 2006). It may be noted that empirical support for this has been shown not only in the case of socially accepted behaviors, but also for activities such as drug use (Williams et al, 2006).

As for the ability of self-prediction questions to affect subsequent behavior (particularly when it comes to socially approved behavior), it has been argued that dissonance mechanisms are likely to be involved; the prediction request is assumed to make individuals aware of what they should do as well as what they have done (or not done) in the past. If these cognitions are discrepant, dissonance occurs. In the next step, in order to reduce dissonance, individuals perform the behavior subject to the self-prediction request (Spangenberg et al, 2003).

Here, however, we are not concerned with the link between questionnaire items and behavior; we are concerned with explicitly requesting a customer - in a face-to-face situation - to engage in WOM. Nevertheless, we believe that similar mechanisms as discussed in the question-behavior effect literature may operate. That is to say, a WOM request is likely to make WOM intentions more accessible (and the request may contribute to forming such intentions in the case in which they initially are non-existing). Given, then, that the request indeed makes intentions more accessible, we would expect a consistency mechanism to contribute to the actual performing of WOM activity. As an alternative and more affective route, there are several potential benefits for a customer to engage in WOM transmission; it may reduce post-purchase dissonance, it may serve to impress others, and it may be a way of helping others making better choices (cf. Ryu and Feick, 2007). Given that many customers are likely to be aware of these aspects, and of their positive affective charge, it is possible that a WOM request increases accessibility to positive memories of previous WOM activities and thus that positive affect associated with prior WOM activity makes it increasingly likely to happen again. It is also possible that engaging in WOM per se represents a positive norm, and thus that an already positive attitude towards WOM would become more accessible - and more causally potent in relation to WOM activity - given a WOM request (cf. Williams et al 2006). These arguments, then, suggest that receiving a request to engage in WOM would have a positive impact on subsequent WOM activity. 


\section{Signaling effects}

Marketing activities, particularly advertising, can be seen as signaling various unobservable characteristics of an offer - such as the firm's confidence in and commitment to its offer which the receiver can use as clues regarding the offer's quality (Kirmani, 1997; Kirmani and Rao, 2000). We assume that an employee's explicit request for WOM can work in the same way; it may signal that the employee is committed to having additional customers to test the offer and therefore that s/he is highly confident regarding the quality of the offer. Given that the WOM request is viewed as a signal in this way, it may affect the customer's WOM activity in two ways. First, the confidence expressed by the request may reduce the customer's perceived social risk of recommending an offer and thereby make WOM activity more likely. Second, confidence and commitment expressed in a WOM request may positively affect the customer's quality perceptions and, in the next step, the customer's overall evaluations. Given a well-established link between overall evaluations and WOM activity (Brown et al, 2005; Mooradian and Olver, 1997), we therefore expect that the request - as a signal - is capable of setting in motion a process in which the net outcome is more WOM activity.

\section{Reciprocity}

Reciprocity mechanisms may also serve to increase the likelihood that a WOM request would result in increased WOM activities. Reciprocity has to do with rewarding kind actions and punish unkind ones (Falk and Fischbacher, 2006) and, in general, there is a strong norm in social situations that encourages individuals to "pay back" in kind what others provide to them (Cialdini, 1987; Dahl et al, 2005; Falk and Fischbacher, 2006). That is to say, given that we humans in general want well-balanced exchange situations, a customer - who has received something from a supplier - may perceive compliance with a WOM request as an opportunity to balance the exchange by providing something in return. This seems particularly likely when the customer is satisfied; in this case, satisfaction may be the asset that demands something in return. 
Marketing literacy and social needs

As an additional way in which a request for WOM may influence WOM activity, our point of departure is that many consumers are increasingly marketing literate, in the sense that they are familiar with the ideas, objectives, and methods of marketing (Macdonald and Uncles, 2007). We therefore expect that such "savvy" consumers have relatively well-developed causal maps covering marketing variables. More specifically, we assume that a supplier's number of customers would be one of the variables in such causal maps, and that this variable is associated with valenced outcome variables. Given this, it seems likely that customers believe that the value they receive in relation to an offer would increase if additional customers choose the same offer. For example, the savvy customer is likely to believe that an increase in the number of a supplier's customers would (1) create better learning opportunities for this supplier and (2) reduce costs for each customer. Both outcomes are likely to result in a better offer for the individual customer, and the mere request for WOM may activate such thoughts and, in the next step, influence WOM activity in a positive way.

Moreover, the customer may value customer-to-customer relations or value membership in a community comprising other customers (Muniz and O'Guinn, 2001). The main benefits of transmitting WOM in this case are thus the positively charged aspects of social belongingness and the possibility of interaction with other customers. In addition, and in relation to the customer's existing social network, several social motives (e.g., self-enhancement, identitysignaling, and the need to fill conversational space) have been identified as drivers of WOM (Berger, 2014). A mere request for WOM may make the value of both additional customers and motives regarding the existing social network accessible in the customer's mind and thereby encourage subsequent WOM activity.

The potential for negative effects

However, asking the customer to provide WOM may produce negative effects in terms of both (a) WOM activity per se and (b) other variables, such as overall evaluations.

More specifically, it is possible that being requested to do something can be perceived as a threat to one's freedom (Clee and Wicklund, 1980; Fitzsimons and Lehman, 2004). This may produce reactance-based attempts to restore freedom by not complying with the request 
(Miron and Brehm, 2006). In a question-behavior effect study, Spangenberg et al (2003) indeed show that commanding people to carry out one particular behavior is less effective than asking for a self-prediction. It should also be noted that making WOM requests within the frame of a face-to-face encounter adds a contextual component, which in turn may affect the response pattern. More specifically, due to several decades of stressing the importance of service in many firms, customers are likely to expect service-related behaviors from employees. Yet a request for WOM is not likely to be part of the typical customer's view of service - instead, this request may serve to make the customer mindful of the commercial purposes of the firm's activities. This means that a WOM request made within the frame of an a service encounter may create a contrast effect with negative implications, in the same sense as the contrast between providing service and making sales attempts in the same encounter can make the customer question the motives behind the service (cf. Söderlund, 2013). Related to this are the observations that many service employees are under increasing pressure to engage more actively in selling activities (Korczynski et al, 2000), which is creating tension for service employees (Leidner, 1993). If making WOM requests is producing the same type of uncomfortable state of mind for service employees (who mainly view themselves as service providers, not as salespersons or marketers) as making selling attempts, it is possible that this rubs off on service employee behavior and thereby negatively affects customers' responses to the request. Thus, from this point of view, merely asking the customer to engage in WOM may result in less WOM activity compared to when no request is made.

Moreover, if a WOM request is perceived as a threat to freedom, it is possible that the request would have a negative impact also on overall evaluations. Indeed, customers pressured to choose one particular option has been shown to react with a less favorable attitude towards this option (Edwards et al, 2002; Wendlandt and Schrader, 2007). That is to say, if the employee is seen as a source of restriction by suggesting what the customer should talk about in his/her personal relationships, we would expect a decrease in the evaluation of the source of the restriction (Fitzsimons and Lehman, 2004). Similarly, if making WOM requests is in conflict with the customer's notion of what "service" is, and if the request is seen as an unexpected and unwelcome commercial element in the midst of a package of service behaviors, then we would expect a negative impact on overall evaluations. In this case, then, the WOM request may be seen as an irritating and annoying tactic in the same way as intrusive ads (cf. Edwards et al, 2002). We do not develop any specific hypotheses regarding the request's potential for impact on overall evaluations, yet in our two empirical studies we 
make attempts to examine empirically if requesting customers to provide WOM has an impact on customers' overall evaluations. If there is a negative association, we assume that this would signal that the act of explicitly asking for WOM may not be a particularly useful practice.

The main hypothesis

Given the conflicting arguments above, we hypothesize that merely requesting the customer to engage in WOM transmission has an impact on the customer's WOM activities. The direction of this impact - if it is positive or negative - will have to be settled in empirical terms. In order to test the hypothesis, and to also assess the potential for an impact on overall evaluations, two empirical studies were made. In Study 1 (a survey-based study) the main hypothesis was tested with correlational analysis, and in Study 2 (an experiment) it was tested by treatment group comparison.

\section{STUDY 1}

Research setting, data collection method and participants

In Study 1, we assessed the mere request hypothesis in a B2C financial service setting. The specific offer was private banking comprising advice regarding investments and asset management; the service supplier was the bank XYZ, and the customers were existing customers to this bank. In this case, XYZ interacted with the customers through specific representatives, personal advisors, which assumed personal responsibility for a set of customers. Typically, the advisor meets with the same customer at several occasions. A convenience sampling approach was used, in the sense that invitations to participate in a questionnaire-based survey was sent from the bank to customers having a personal advisor, and those customers who responded positively to the invitation were used for the analysis $(n=$ 166,57 percent male customers, $\left.M_{\text {age }}=62.11\right)$. This sample comprises customers from three of the countries in which XYZ is active $\left(n_{\text {country } A}=48, n_{\text {country } B}=68, n_{\text {country } C}=50\right)$. The level reached by the variables reported below were not subject to significant differences between the three countries; therefore, the subsequent analyses were made at the total sample level. 
Measures

Word-of-mouth is typically defined as informal communication between customers regarding commercial experiences (Anderson, 1998), meaning that basically any comments about such experiences would count as WOM (cf. Sweeney et al, 2012). In practice, however, much empirical WOM research is focused on explicit recommendation content in customer-tocustomer conversations. Therefore, we decided to have such a recommendation focus in our measures of both requests for WOM and WOM activity.

With respect to requests for WOM, the perhaps most intuitive measurement option might be to view the underlying construct in dichotomous terms (i.e., either requests occur or not). Yet in our case we are dealing with consumer-firm representative relations with a relative long duration and involving several encounters. This means that one representative can make several requests to the same customer over time. Ideally, then, a request for WOM measure would be of the ratio scale type to capture the magnitude of requests and thus not only if they have occurred or not. However, given long-term relations with several encounters, and with much other conversational content than requests for WOM, we felt this would invite memorybias problems. To be able to capture more information than if requests had occurred or not, we therefore decided to use an interval scaled-based measure. More specifically, we employed the question "My personal advisor has explicitly asked me to recommend XYZ's private banking services to persons I know", which was scored on a scale ranging from 1 (do not agree at all) to 10 (agree completely).

Customers' WOM activity is typically measured in terms of self-reported activity, because of the difficulties involved in capturing WOM while it occurs. We relied on such self-reports, too. More specifically, WOM activity was assessed in two ways. First, WOM behavior was measured with the question "How many persons have you recommended to become a XYZ private banking customer?". It was followed by an open-ended response space to capture the number of persons subject to WOM transmission. Such number-of-persons-based measures of WOM activity have been employed by, for example, Anderson (1998) and Bowman and Narayandas (2001). Second, we used a WOM intention measure that appear frequently in the literature and is particularly advocated by Reichheld (2003). The question was "How likely is it that you would recommend someone to become a XYZ private banking customer?", and it 
was scored on a scale ranging from 1 (very unlikely) to 10 (very likely). Single-item measures of WOM intentions of this type have been used by, for example, Hartline and Jones (1996). Such items are also the basis for computing the so-called net promoter metric, which has been widely embraced particularly by managers (Gupta and Zeithaml, 2006; Keiningham et al, 2007).

To be able to identify possible negative effects of WOM requests, we included two overall evaluation measures. The idea, as indicated above, was that a negative association between receiving a WOM request and overall evaluations would indicate if the request has negative effects. First, we assessed the overall evaluation of the personal advisor in terms of satisfaction with the advisor. We asked the following question: "What is your overall impression of your XYZ personal advisor?” followed by three customer satisfaction items employed in several national satisfaction barometers (Fornell, 1992; Johnson et al., 2001): "How satisfied or dissatisfied are you with your personal advisor?" ( 1 = very dissatisfied, 10 = very satisfied), "To what extent does your personal advisor meet your expectations?" $(1=$ not at all, $10=$ totally), and "Imagine a personal advisor that is perfect in every respect. How near or far from this ideal do you find your personal advisor?" (1 = very far from, 10 = cannot get any closer). Cronbach's alpha for this scale was .94, and we used the unweighted average of the responses as a single customer satisfaction variable in the analysis. Second, we assessed overall satisfaction with the bank with the statement " $\mathrm{XYZ}$ is really committed to satisfy my needs", which was scored on a 10-point scale $(1=$ do not agree at all, $10=$ agree completely). These two evaluation variables were positively associated $(r=.67, p<.01)$. Conceptually, however, they reflect different levels of evaluations and we therefore used them as separate variables.

It should thus be noted that the most of our measures were of the single-item type. We do agree with authors such as Churchill (1979) who advocate multi-item measures, particularly for assessments of reliability in terms of internal consistency. Yet it must be acknowledged that practitioners are not always convinced of the usefulness of several questions that appear to capture the same construct. This was indeed the case in Study 1, in which we had to adapt our measures to the views of XYZ in order to get access to its customers in the first place. In any case, and given copious studies arguing (and demonstrating empirically) that global evaluations, particularly customer satisfaction, are contributing positively to WOM activity (e.g., Brown et al, 2005; Mooradian and Olver, 1997), we used our two evaluation variables to 
examine the nomological validity in the WOM activity measures. That is to say, if positive associations would occur also in our present case, it would indicate that our WOM activity items measure what they are supposed to measure. Positive associations were indeed at hand; satisfaction with the personal advisor was positively associated with both WOM behavior $(r=$ $.22, p<.01)$ and WOM intentions $(r=.48, p<.01)$. Satisfaction with the bank exhibited similar associations with the two WOM activity variables $(r=.29, p<.01 ; r=.57, p<.01)$. See also Table 1 for means standard deviations, and zero-order correlations for the main variables.

Analysis and results

Our main hypothesis - that merely requesting the customer to engage in WOM transmission would have an impact on the customer's WOM activity - was assessed by correlational analysis. More specifically, we used the zero-order correlations between the WOM request variable and the two WOM activity variables (i.e., WOM behavior and WOM intentions); we thus assumed that significant associations would indicate an impact. With respect to WOM behavior, the association was positive and significant $(r=.19, p<.05)$. A similar pattern was obtained for the WOM intention variable $(r=.24, p<.01)$. We thus contend that the main hypothesis was supported (cf. Table 1).

-Table 1 here-

The possibility that asking for WOM may backfire, and thus produce negative effects, was examined in two ways. First, we examined the association between the WOM request variable and satisfaction with the personal advisor. This association was positive but non-significant $(r$ $=.07, p=.38$ ). Thus merely asking the customer to transmit WOM does not seem to have a negative impact on the overall evaluation of the person who asks for WOM. Second, we examined the association between the WOM request variable and overall satisfaction with the bank. In this case, the association was somewhat stronger, positive and significant $(r=.16, p$ $<$.10). This thus indicates that merely asking the customer to provide WOM may actually contribute positively to the customer's overall impression of the firm (the effect size, however, is modest). 
Discussion

Study 1 took place in a service setting, and researchers interested in the impact of WOM on receivers have argued that such settings make WOM a particularly important source for potential customers due to the heterogeneity of service quality, higher risks, and the intangible nature of services (Lim and Chung, 2011). It is also possible, however, that the same characteristics makes transmitters more likely to engage in WOM activity, and that a mere request to engage in WOM would be a relatively more potent trigger of WOM activity in a service setting. Moreover, Study 1 was a survey-based correlation study, which has wellknown drawbacks for causal inferences. And the measure of WOM requests in Study 1 can be seen as ambiguous in terms of the scaling choice. That is to say, our 10-point scale measure of the extent to which the participants were explicitly asked by the personal advisor to recommend XYZ offers relatively little precision in terms of both presence/absence of requests and the number of requests that were made for each customer. Our request for WOM variable was indeed subject to variation $(M=4.85, S D=3.33)$, and the lowest scale value (i.e., 1) was used by 21 percent of the participants, thus indicating that some of the participants were not subject to WOM requests. Yet this type of measure does not allow for an explicit comparison of WOM activity levels between participants who had been subject to a request for WOM and those who had offered WOM in an unsolicited way. In addition, Study 1 did not reveal anything about what the personal advisors actually said to the customers when they were making requests for WOM. Therefore, to deal with these limitations, and to see if the results would replicate, an additional study was carried out in another empirical context, with an experiment, and with the request for WOM as a dichotomous experimental factor and thus something which allows for explicit control of the content of the WOM request.

\section{STUDY 2}

Research setting, data collection method and participants

In Study 2, we examined the mere request hypotheses in a retail setting and with a betweensubjects experiment in which the participants were exposed to an employee who either did not or did make an explicit request for WOM. More specifically, we used a text-based role-play 
scenario approach. Such an approach has been used frequently in service research in general (e.g., Bitner, 1990; Dallimore et al., 2007; Karande et al., 2007) and in word-of-mouth research (e.g., Lim and Cheung, 2011; Meuter et al, 2013; Söderlund and Rosengren, 2007; Van Vaerenbergh et al, 2012; Wien and Olsen, 2014). One main advantage is that it allows for control of factors others than those that are manipulated. Another advantage is that it may be used to assess factors which can have negative consequences (and such factors may be difficult to examine in field settings in which cooperation with firms is required for access to participants). In relation to Study 1, in which we relied heavily on the participants' memories of requests for WOM and for WOM activity in terms of behavior, it can be noted that a scenario-approach with measures taken immediately after the treatment is likely to reduce memory biases (Wien and Olsen, 2014).

In our case, the participants were asked to assume the role of a customer who was in a sport store to purchase an activity wristband as a birthday present for a friend. The scenario described how a customer interacted with a professional and service-oriented employee, and it ended with the customer purchasing a wristband. Two versions of the scenario ending were created. In the first version, the employee made no request for WOM; in the second version, and while the customer was in process of paying, the employee did make a request for WOM. The specific wording of the request was this: "Please recommend us to people you know!" (see Appendix 1 for the full scenario). The absence or presence of this request was the only difference between the two scenario versions. The two scenario versions were distributed randomly to the participants, and the scenario text was followed by the questionnaire items reported below. The participants ( $n=75, M_{\text {age }}=35.44$ years; 34 men and 41 women) were recruited from (a) decision makers who took part in a breakfast lecture, (b) master-level students in a business administration program, and (c) bachelor-level students in a business administration program. A $3 \times 2$ ANOVA with participant type (decision maker, master student, bachelor student) and treatment group (no WOM request vs. WOM request) and WOM intentions as the dependent variable revealed that there was no significant main effect of participant type (and no significant interaction effect), and therefore no further analysis was made with respect to participant type. In any event, we thus used a convenience sampling approach comprising student participants, something considered adequate in studies attempting to test general theoretical propositions (such as in the present case) rather than generalizing from data (Calder et al, 1981; Calder et al, 1982). 
Measures

For WOM activity, we employed a single-item WOM intention measure of the type recommended by Reichheld (2003) and similar to what we used in Study 1: "How likely is it that you would recommend this store to people you know?". It was scored on a scale ranging from 1 (very unlikely) to 10 (very likely).

To be able to identify the potential for negative effects of WOM requests, and to obtain results that would be comparable to Study 1, we asked the participants about their (a) evaluation of the salesperson and (b) overall evaluation of the store. For the first evaluation variable, we asked about the attitude toward the salesperson with three adjective pairs (bad-good, dislikelike, and unpleasant-pleasant) scored on a 10-point scale (Cronbach's alpha $=.93$ ). As for the second evaluation variable, we used customer satisfaction. More specifically, we asked the following question: "What is your overall impression of the store after this visit?". It was followed by three satisfaction items used in several national satisfaction barometers (Fornell, 1992; Johnson et al., 2001): "How satisfied or dissatisfied are you with this store?" (1 = very dissatisfied, 10 = very satisfied), "To what extent does this store meet your expectations?" (1 $=$ not at all, $10=$ totally), and "Imagine a sport store that is perfect in every respect. How near or far from this ideal do you find this store?” ( 1 = very far from, $10=$ cannot get any closer). Alpha for this scale was .93. Again, as in Study 1, the two evaluation variables were positively associated $(r=.81, p<.01)$. Yet in a conceptual sense they reflect different levels of evaluations and we therefore used them as two separate variables. In addition, we measured repatronize intentions with the item "How likely is it that you would visit this store again?", scored on 10-point scale ( 1 = very unlikely, $10=$ very likely). The main rationale behind this item was that reduced repatronize intentions given a WOM request would signal negative consequences of the request.

As a manipulation check, and at the very end of the questionnaire, we used the item "The salesperson asked me to recommend this store" scored on a scale ranging from 1 (do not agree at all) to 10 (agree completely). It should be noted that this item is basically the same as the item we used to measure the WOM request variable in Study 1. In any case, given our manipulation, we expected that the response level should be lower for the respondents who were not exposed to the WOM request. In addition, and given a concern among researchers that participants may not read instructions properly, particularly when MTurk data collections 
are growing in popularity, we included (again at the end of the questionnaire) an item intended as an instructional manipulation check (cf. Goodman et al, 2012). It was worded as follows: "The salesperson made an attempt to sell an activity wristband also to me", scored on a scale ranging from 1 (do not agree at all) to 10 (agree completely). Please recall that the participant's task was to purchase a wristband for a friend's birthday, yet in both scenario versions the salesperson made an attempt to sell a wristband for personal use by the participant (cf. Appendix 1). For this item we thus expected high response levels for both treatment groups (given that they had understood the scenario text).

Finally, we assessed scenario realism with an item dealing with how it felt being in the store; we used the adjective pair "unrealistic-realistic" scored on a 10 point scale (a similar item was used by Karande et al, 2007). The perceived realism did not differ significantly between the two scenario versions $(t=1.01, p=.32)$, and the overall sample mean for the realism variable $(M=7.14)$ was significantly higher than the scale midpoint $(t=7.65, p<.01)$. We therefore conclude that the participants perceived the scenario texts as relatively high in realism.

Analysis and results

The manipulation check with the item "The salesperson asked me to recommend this store" revealed that the participants who were exposed to a request for WOM responded with a higher level of agreement $(M=9.81)$ than those who were not exposed to the request $(M=$ 3.53). This difference was significant $(t=14.22, p<.01)$. The instructional manipulation check, for which we expected high and similar response levels for both groups, showed that the response level in the WOM request group $(M=9.35)$ was not significantly different $(t=$ $.40, p=.69)$ from the group not exposed to a WOM request $(M=9.24)$. It can be contended, then, that the manipulation behaved as expected (and that the participants had understood what happened in the scenario texts).

The main hypothesis (i.e., merely requesting the customer to engage in WOM transmission has an impact on the customer's WOM activities) was tested by comparing the mean response levels for the WOM intention variable in the two groups. In contrast to the correlational-based assessment in Study 1, mean level responses were thus used in Study 2 to assess impact. This comparison revealed that WOM intentions reached a higher level for the participants $(n=38)$ exposed to a request for WOM $(M=7.51)$ in relation to those participants $(n=37)$ who were 
not exposed to the WOM request $(M=6.00)$. This difference was significant $(t=2.82, p<$ $.01)$. The main hypothesis was thus supported.

Moreover, as in Study 1, we examined the possibility that asking for WOM may produce negative effects. We did this by assessing the associations between our manipulation check item ("The salesperson asked me to recommend this store") and the two evaluation variables. For the attitude towards the salesperson, this association was positive and significant $(r=.24$, $p<.05)$. A similar outcome was obtained for customer satisfaction $(r=.27, p<.05)$. This thus indicates that merely asking the customer to provide WOM may contribute positively to the customer's attitude toward the person making the request and to the overall impression of the firm. In addition, the manipulation check item was positively associated with the repatronize intention item $(r=.23, p<.10)$, thus providing further evidence regarding the positive charge of the WOM request. It can be noted that a similar analysis of the other request made by the salesperson (i.e., that the participant should buy an activity wristband also for him/herself and thus not only for the friend's birthday) produced non-significant associations with the attitude toward the salesperson $(r=.03, p=.80)$ and customer satisfaction $(r=.01, p=.90)$. Hence, to ask for WOM may be perceived as a conceptually different type of request, and a more positively charged request, compared to asking the customer to purchase something.

\section{Discussion}

The results in Study 1 (from a field setting) were replicated in the scenario-based experiment in Study 2, in the sense that the main findings indicate that a mere request for WOM had a positive impact on WOM activity and no negative impact on evaluations. The main advantage with experiments is that they allow for less ambiguity when it comes to causal inference, yet some traditional experimenters in social psychology, such as Aronson and Carlsmith (1968), view scenario situations as relatively artificial. Other researchers, however, argue that results from scenario approaches do replicate in field settings (Bateson and Hui, 1992), but this remains to be tested in the specific case of requests for WOM. Because manipulations in a field setting would be relatively uncomplicated (i.e., employees can be instructed to deliver a request for WOM to some customers and to withhold such a request for other customers), further studies should indeed examine this issue in a field setting. In addition, Study 1 never revealed the actual content of WOM requests, yet in Study 2 the manipulation allowed us to 
examine at least one particular type of request for WOM ("Please recommend us to people you know!"). Needless to say, however, such requests can be made in several other ways, and this is an issue we return to below.

\section{GENERAL DISCUSSION}

Summary of main findings

Our results indicate that merely requesting a customer to engage in WOM transmission had a positive impact on WOM behavior (Study 1) and on WOM intentions (Study 1 and Study 2). A mere request for WOM thus seems to make WOM activity more likely to happen. In addition, in both studies, we found that requesting WOM did not appear to have had a negative influence on customers' overall evaluations. Thus, the potential for negative effects of making the request seems to be negligible. In fact, Study 1 and particularly Study 2 indicate that a request for WOM can have positive effects on overall evaluations.

\section{Contributions}

Our study contributes to the WOM literature comprising antecedents to WOM transmission by demonstrating that a mere request to engage in WOM, by an employee in a face-to-face encounter, has a positive impact on WOM activity. To date, this particular factor has not been examined in WOM literature.

A related issue, however, has been examined previously - namely the so-called questionbehavior effect. That is to say, merely asking a behavior-related question in a questionnaire, typically an intention question, has been shown to affect subsequent behavior related to the question. Hence scholars in this field have concluded that this phenomenon has important real-world applications, in the sense that those interested in social influence can use questions to alter behavior (Sprott et al, 2006). Yet research in this field has focused on questions in questionnaires. Our results contribute to this literature, then, by showing that a request in a face-to-face encounter appears to be able to produce both intention effects and behavioral effects. 
We also believe that our results contribute to the literature dealing with the effects of explicitly asking customers to carry out activities. So far, this literature has covered crossselling attempts (Söderlund, 2013) and asking customers to participate in satisfaction surveys (Jones et al, 2014), but to date it has not dealt with WOM requests. In more general terms, our results highlight the importance of what is said to customers in face-to-face conversations, an area that we believe have been neglected in recent years, because many contemporary marketing researchers seem to be relatively more interested in subtle means of influence such as nudging, experience-enhancing atmospheric elements, visually juxtaposing their brands with various images and in online marketing activities in which no interaction at all takes place between customers and individual employees.

\section{Managerial implications}

Our results imply that managers who would like to boost customers' WOM activity may do so by encouraging employees to make WOM requests within the frame of service encounters. Many firms - particularly chain operations - already use scripts to control employee behavior in customer interactions, and it seems to be easy to extend existing scripts by explicitly including requests for WOM activity (e.g., "Ask every customer to recommend us to his/her friends"). Given that managers serve as role models for employees, it also appears to be fruitful if managers themselves make such requests when interacting with customers.

It should be underscored that a request of this type is cost-efficient; it costs very little to make the request, and our results indicate that it is a harmless activity (at least from a satisfaction point of view). The cost-efficiency issue should be seen in the light of some other activities suggested in the literature to boost WOM activity, such as referral reward programs (Ryu and Feick, 2007; Verlegh et al, 2013; Xiao et al, 2011) and promotional give-aways (Berger and Schwartz, 2014), which are obviously less cost-efficient than a mere request. Again, as already mentioned, a request for WOM seems to be able to generate compliance in a way that is similar to cross-selling attempts - in the sense that a suggestion that the customer should buy an additional item has been shown to have a positive effect on buying behavior and thus on sales (Söderlund, 2013). 
Limitations and suggestions for further research

As observed by several authors, such as Peterson and Wilson (1992), the distribution of overall customer satisfaction in the typical empirical study is negatively skewed (i.e., the most customers are satisfied rather than dissatisfied). One main reason - in a reasonably wellfunctioning market - is that customers would avoid poorly performing firms (cf. Fornell, 1992). Skewness of this type in the overall satisfaction scores was indeed at hand in both our studies (Study 1: $M_{\text {satisfaction }}=7.07$, skewness $=-0.38$; Study 2: $M_{\text {satisfaction }}=8.12$, skewness = 1.23). This thus means that our results were obtained in a situation with firms performing at a relatively high level and in which most customers were satisfied rather than dissatisfied. Clearly, however, many firms also have dissatisfied customers. Yet for dissatisfied customers, a request for WOM is not likely to be effective. It may even backfire and create less WOM activity, because a request for WOM to a dissatisfied customer may signal a very low level of empathy. A WOM request in this situation may also have a negative impact on overall satisfaction, because it may suggest that the firm has not understood that it has created a service failure and that the firm has no intentions to engage in recovery activities. In other words, our results should be seen as restricted to a high opposed to a low customer satisfaction situation and further research is thus needed to examine effects of WOM requests in the low satisfaction condition.

Moreover, as already mentioned, the WOM request measure in Study 1 did not reveal the explicit wording of the requests that the participants were exposed to. In contrast, in Study 2 the wording was indeed explicit ("Please recommend us to people you know!") because it was subject to our manipulation. Presumably, however, different ways of making the request may have different effects on compliance (and on overall evaluations). It may be noted that research on the question-behavior effect in questionnaires indicates that the behavioral effect tends to be larger given specific questions (Sprott et al, 2006). Translated to a request for WOM in a service encounter, one may therefore speculate that specific requests (e.g., "Please recommend us to your best friend who may need the same service as you") would have different implications for WOM activity than more general requests (e.g., "Please recommend us to your friends"). It has also been argued - again in the question-behavior effect literature that direct commands (e.g., Buckle up!" and "Just say no to drugs!") are less likely to have positive behavioral effects (Spangenberg et al, 2003). Further research should therefore examine the impact of making WOM requests in different ways. Politeness theory (Brown 
and Levinson, 1978) may be useful as a guide to the ways in which requests can be made. Reactance theory (cf. Miron and Brehm, 2006) may also be useful in identifying requests with different implications for perceptions of freedom being lost or threatened.

In addition, we examined WOM requests in terms of verbal messages from a firm representative to a customer in a face-to-face context. Yet requests for WOM can be made also in other ways, and the effectiveness of such ways calls for further examination. An analogy is that cross-selling attempts do not always involve a direct question from a salesperson; such attempts can also be made, for example, in printed material (Söderlund, 2013). For example, in one electronics retail chain, the employees at the checkout wear tshirts with the text "You haven't forgotten batteries, have you?". Spangenberg et al (2003) have shown that question-behavior effects may occur also outside a questionnaire context; they show that self-prediction requests made in terms of mass communicated messages can have similar behavioral implications as questionnaire items. Therefore, explicit comparisons of different channels (e.g., employee t-shirts, store signs, and printed ads) in which WOM requests could be made is an important issue for further research. We suspect, however, that the effectiveness of the WOM request is predicated on its occurrence in conversations with also other content. Yet this other content can indeed be subject to variation, and an additional issue for further research is if different types of conversation content may condition the impact of WOM requests.

In conceptual terms, we offered several (and conflicting) arguments regarding the mechanisms by which a mere request for WOM is likely to have an impact on WOM activity. Given that our results show that WOM requests have a positive rather than a negative impact on WOM activity, the arguments in favor of a positive association are thus likely to comprise mechanisms responsible for the association. For example, consistency, reciprocity, and signaling mechanisms may be involved. Yet neither our Study 1 nor our Study 2 contained explicit attempts to address such mechanisms in empirical terms. This represents another limitation. Further research should thus make attempts to measure variables with a potential to explain why a mere request for WOM is likely to affect WOM activity. In addition, given that psychological reactance is likely to be an individual difference variable (Dowd et al, 1991), there may be personality-related differences between customers that affect how they react to requests by employees. This aspect calls for attention in future research, too. 
A related issue is what links we actually examined for the existing variables. What we did focus on was if WOM requests would have an impact on (a) WOM activity and (b) evaluations (such as customer satisfaction). In the latter case, customer satisfaction was thus assumed to be an effect variable in relation to WOM requests. Yet this is not the only role satisfaction can play in the case at hand here. In the introduction, we noted that many authors (e.g., Anderson, 1998; Ranaweera and Prabhu, 2003; Sweeney et al, 2012; Westbrook, 1987) have identified a positive and significant association between customer satisfaction and WOM activity. Such authors also typically assume that satisfaction is the cause variable and that WOM activity is the effect variable. Moreover, we have indicated that satisfaction is likely to be a moderating variable, in the sense that our main findings were obtained in a situation in which most customers were satisfied rather than dissatisfied. Given our use of satisfaction as an effect variable in relation to WOM requests (as an attempt to examine the potential for negative consequences of WOM requests) and given the positive satisfaction-WOM activity link in existing literature, however, this implies that satisfaction would be a potential mediating variable in the request for WOM-WOM activity link. From a conceptual point of view, all of these roles seem to make sense, yet our two studies would not allow a serious attempt to disentangle the roles of satisfaction in empirical terms. This must thus be the task for further research. As for the mediation part of such undertakings, the solution may appear obvious, at least in the light of currently popular and easy to use algorithms for mediation analysis (Zhao et al, 2010), yet convincing arguments exist for manipulating rather than measuring mediating variables (Spencer et al, 2005). This clearly calls for a more complex experimental design than what we used in Study 2.

Furthermore, both Study 1 and Study 2 were unspecific with respect to how the participants had transmitted WOM (in the case of behavior) or would transmit WOM (in the case of intentions). That is to say, our measures did not capture WOM activity so that it would be possible to make distinctions between face-to-face WOM and electronic WOM. Some authors, however, claim that face-to-face WOM is more common and is more trustworthy than electronic WOM (Berger and Schwartz, 2014; Sweneey et al, 2014), and that face-toface WOM has a stronger impact on the receiver than electronic WOM (Meuter et al, 2013). At the same time, much current WOM research seems to take place solely in an online context. In any event, further research on the impact of WOM requests on WOM activity may produce a richer picture if WOM activity is explicitly captured in terms of both face-to-face WOM and electronic WOM. 
It should also be noted that both Study 1 and Study 2 focused on the transmission side of WOM, thus leaving out the receiver of WOM and his/her reactions. Including the receiver, however, would enlarge the scope of our results. It does seem clear that rewarded WOM reduces the effectiveness in relation to unrewarded WOM (Verlegh et al, 2013), but what would happen if the transmitter says - in the process of transmitting WOM - to the receiver that $\mathrm{s} /$ he has been asked to provide WOM (without any reward being involved)? Would the receiver react differently when knowing that the transmitter has been requested to provide WOM compared to when no request exists? Some research on customer-to-customer communication in social media indicates that receivers of messages react differently if they are given information about the presence of a commercial sponsor as opposed to when no sponsor is revealed (Colliander, 2012). Therefore, further research on the mere request for WOM should examine the receiving aspect, too. In addition, the receiver may initiate WOM from a transmitter, which has been shown to make WOM more effective (Verlegh et al, 2013). Would this situation (i.e., receiver-driven WOM) produce differences in receiver responses if the receiver gets to know that the transmitter has been requested to engage in WOM? Not much is known about this.

Finally, we noted that the customer's persuasion knowledge may increase resistance to messages. Customers, however, possess also other types of knowledge, such as general marketing knowledge. And in an era in which more or less every person is supposed to view $\mathrm{him} / \mathrm{h}$ erself as a brand to be sold in the market, and in which social media are available as marketing tools for almost any individual, it can be expected that many customers today have a "marketing mindset" in terms of being marketing literate (cf. Macdonald and Uncles, 2007). We believe that various WOM aspects is a part of this mindset, particularly when so many firms communicate that WOM is important (e.g., by asking WOM intention questions in questionnaires), and that such a mindset may have an impact both on the transmitter's compliance with WOM requests and on the receiver's reaction to WOM originating from a firm's request to a transmitter. For example, customers who believe that it is a wise practice for firms to make attempts to generate WOM may react differently than those customers who are ignorant of conceptual WOM aspects. Thus, customers' conceptual knowledge of WOM is likely to be subject to variation, and it seems imperative to include also this aspect in further assessments of requests for WOM. 


\section{Appendix 1*}

\section{Imagine this:}

Someone you know will soon have a birthday. You need to buy a present. This person has a specific wish: a training wristband. Not just any such wristband, but a black UP Jawbone Medium. So your task is to try to find this product as a birthday gift for your friend. When you walk on a street in an area in which you have not been for some time, you discover a new sport store. You decide to enter to see if they have the training wristband that you are looking for.

You immediately find a salesperson who says hello to you asks if you need help. This salesperson looks very fit. You ask if the store sells training wristbands. "Yes, indeed we do", says the salesperson, "but we call them activity trackers. What kind of training do you do?" You explain that the band is not for you; you are supposed to give it away as a present, and you also explain that you specifically look for a Jawbone wristband.

"Good choice! I have tested several activity trackers myself. And I really like the Jawbone app", says the salesperson. You ask what the app is doing, and while the salesperson brings you to the activity tracker section the salesperson says that you connect the band to a mobile telephone in which an app keeps track of your training activities. The salesperson says that you can also use the band to keep track of sleeping activities - and of eating habits. When you arrive at the activity tracker section you see that the assortment is indeed wide. And you see the black UP Jawbone Medium. You say that this is the product you want. It costs SEK 1190.

"OK! This product is water resistant, but not 100 percent waterproof. So you should not go swimming with it. A perfect complement to an active lifestyle! How was is, did you train yourself?", asks the salesperson. You tell the salesperson what the situation is like, and the salesperson asks if you may consider buying an activity tracker also for yourself. You say that you'll think about it.

While you pay the salesperson says that the activity tracker is good for your training motivation and that it gives you an interesting perspective on your habits in general. It is shock resistant, too - and you can wear it in the shower. You say that you have not seen this store before. The salesperson says that it has been around only for a couple of weeks and that the store makes a serious attempt to have a wide assortment of activity trackers. "Please recommend us to people you know!", says the salesperson. When you have finished paying the salesperson says thank you, and you go out on the street with the Jawbone UP Medium. The birthday present task has been completed.

*The absence or presence of the sentence in bold text represents the only difference between the two scenario versions. 


\section{References}

Anderson, E.W. (1998), Customer satisfaction and word of mouth, Journal of Service Research, 1 (1), 5-17.

Aronson, E. and Carlsmith, J.M. (1968), Experimentation in social psychology. In: Lindzey, G. and Aronson, E. (Eds.), The Handbook of Social Psychology, 2, Reading, Massachusetts: Addison-Wesley Publishing Company.

Bateson J.E.G. \& Hui M.K. (1992), The ecological validity of photographic slides and videotapes in simulating the service setting, Journal of Consumer Research, 19 (September), 271-281.

Berger, J. (2014), Word of mouth and interpersonal communication: A review and directions for future research, Journal of Consumer Psychology, 24 (4), 586-607.

Berger, J. and Schwartz, E.M. (2014), What drives immediate and ongoing word of mouth?, Journal of Marketing Research, 48 (October), 869-880.

Bitner, M.J. (1990), Evaluating Service Encounters: The Effects of Physical Surroundings and Employee Responses, Journal of Marketing, 54 (April), 69-82.

Blackwell, R.D., Miniard, P.W. and Engel, J.F. (2001), Consumer Behavior, Fort Worth: Harcourt College Publishers.

Bone, P.F. (1992), Determinants of word-of-mouth communications during product consumption, Advances in Consumer Research, 19, 579-583.

Bowman, D. and Narayandas, D. (2001), Managing customer-initiated contacts with manufacturers: The impact on share of category requirements and word-of-mouth behavior, Journal of Marketing Research, 38 (August), 281-297.

Brown, P. and Levinson, S.C. (1978), Politeness: Some universals in language usage, New York: Cambridge University Press.

Brown, T.J., Barry, T.E., Dacin, P.A. and Gunst, R.F. (2005), Spreading the word: Investigating antecedents of consumers' positive word-of-mouth intentions and behaviors in a retailing context, Journal of the Academy of Marketing Science, 33 (2), 123-138.

Calder, B.J., Philips, L.W. and Tybout, A.M. (1981), Designing research for application, Journal of Consumer Research, 8 (September), 197-207.

Calder B.J., Philips, L.W. and Tybout, A.M. (1982), The concept of external validity. Journal of Consumer Research, 9 (December), 240-244

Chandon, P., Morwitz, V.G. and Reinartz, W.J. (2005), Do intentions really predict behavior? Self-generated validity effects in survey research, Journal of Marketing, 69 (April), 1-14. 
Cheung, M.-S., Anitsal, M.M. and Anitsal, I. (2007), Revisiting word-of-mouth communications: A cross-national exploration, Journal of Marketing Theory and Practice, 15 (3), 235-249.

Churchill, G.A. (1979), A paradigm for developing better measures of marketing constructs, Journal of Marketing Research, 6 (February), 64-73.

Cialdini, R.B. (1987), Influence: Science and Practice, USA: Harper Collins Publishers.

Clee, M.A. and Wicklund, R.A (1980), Consumer behavior and psychological reactance, Journal of Consumer Research, 6 (March), 389-405.

Colliander, J. (2012), Socially acceptable? Exploring consumer responses to marketing in social media, Ph. D. Thesis, Stockholm School of Economics, Stockholm, Sweden.

Dahl, D.W., Honea, H. and Manchanda, R.V. (2005), The three R's of interpersonal guilt: Relationship, reciprocity, reparation, Journal of Consumer Psychology, 15 (4), 307-315.

Dallimore, K.S., Sparks, B.A. and Butcher, K. (2007), The influence of angry customer outbursts on service providers' facial displays and affective states, Journal of Service Research, 10 (1), 78-92.

Danaher, P.J. and Rust, R.T. (1996), Indirect financial benefits from service quality, Quality Management Journal, 3 (2), 63-75.

Dichter, E. (1966), How word-of-mouth advertising works, Harvard Business Review, 44 (6), 147-166.

Dowd, E.T., Milne, C.R. and Wise, S.L. (1991), The therapeutic reactance scale: A measure of psychological reactance, Journal of Counseling \& Development, 69 (July/August), 541545.

Edwards, S.M., Li H. and Lee, J.-H. (2002), Forced exposure and psychological reactance: Antecedents and consequences of the perceived intrusiveness of pop-up ads, Journal of Advertising, 31 (3), 83-95.

Falk, A. and Fischbacher, U. (2006), A theory of reciprocity, Games and Economic Behavior, 54, 293-315.

Fitzsimons, G.J. and Lehmann, D.R. (2004), Reactance to recommendations: When unsolicited advice yields contrary responses, Marketing Science, 23 (1), 82-94.

Fornell, C. (1992). A national satisfaction barometer: The Swedish experience, Journal of Marketing, 56 (January), 6-21.

Friestad, M. and Wright, P. (1994), The persuasion knowledge model: How people cope with persuasion attempts, Journal of Consumer Research, 21 (1), 1-31.

Fullerton, G. (2005), The impact of brand commitment on loyalty to retail service brands, Canadian Journal of Administrative Sciences, 22 (2), 97-110. 
Gelb, B. and Johnson, M. (1995), Word-of-mouth communication: causes and consequences, Marketing Review, 15 (3), 54-58.

Gremler, D.D., Gwinner, K.P. and Brown, S.W. (2001), Generating positive word-of-mouth communication through customer-employee relationships, International Journal of Service Industry Management, 12 (1), 44-59.

Goodman, J.K., Cryder, C.E. and Cheema, A. (2012), Data collection in a flat world: The strengths and weaknesses of Mechanical Turk samples, Journal of Behavioral Decision Making, 26 (3), 213-224.

Gupta, S. and Zeithaml, V. (2006), Customer metrics and their impact on financial performance, Marketing Science, 25 (6), 718-739.

Hartline, M.D. and Jones, K.C. (1996), Employee performance cues in a hotel service environment: influence on perceived service quality, value, and word-of-mouth intentions, Journal of Business Research, 35 (3), 205-217.

Jones, M.A., Taylor, V.A. and Reynolds, K.E. (2014), The effect of requests for positive evaluations on customer satisfaction ratings, Psychology \& Marketing, 31 (3), 161-170.

Johnson, M. D., Gustafsson, A., Andreassen, T.W., Lervik, L. and Cha, J. (2001), The evolution and future of national satisfaction index models, Journal of Economic Psychology, $22(2), 217-245$.

Karande, K., Magnini, V.P. and Tam, L. (2007), Recovery voice and satisfaction after service failure, Journal of Service Research, 10 (2), 187-203.

Keiningham, T.L., Cooil, B., Wallin Andreassen, T. and Aksoy, L. (2007), A longitudinal examination of net promoter and firm revenue growth, Journal of Marketing, 71 (July), 39-51.

Kirmani, A. (1997), Advertising repetition as a signal of quality: If it's advertised so much, something must be wrong, Journal of Advertising, 24 (3), 77-86.

Kirmani, A. and Rao, A.R. (2000), No pain, no gain: A critical review of the literature on signaling unobservable product quality, Journal of Marketing, 64 (April), 66-79.

Korczynski, M., Shire, K., Frenkel, S. and Tam, M. (2000), Service work in consumer capitalism: Customers, control and contradictions, Work, Employment \& Society, 14 (4), 669687.

Kumar, V., Petersen J.A. and Leone, R.P. (2007), How valuable is word of mouth?, Harvard Business Review, 85 (10), 139-146.

Leidner, R. (1993) Fast Food, Fast Talk: Service Work and the Routinization of Everyday Life, Berkeley, CA: University of California Press.

Lim, B.C. and Chung, C.M.Y. (2011), The impact of word-of-mouth communication on attribute evaluation, Journal of Business Research, 64 (1), 18-23. 
Macdonald, E.K. and Uncles, M.D. (2007), Consumer savvy: Conceptualization and measurement, Journal of Marketing Management, 23 (5-6), 497-517.

Mangold, W.G., Miller, F. and Brockway, G.R. (1999), Word-of-mouth communication in the service marketplace, The Journal of Services Marketing, 13 (1), 73-89.

Meuter, M.L., Brown McCabe, D. and Curran, J.M. (2013), Electronic word-of-mouth versus interpersonal word-of-mouth: Are all forms of word-of-mouth equally influential?, Services Marketing Quarterly, 34 (3), 240-256.

Miron, A.M. and Brehm, J.W. (2006), Reactance theory - 40 years later, Zeitschrift für Sozialpsychologie, 37 (1), 3-12.

Mooradian, T.A. and Olver, J.M. (1997), "I can't get no satisfaction": The impact of personality and emotion on postpurchase processes, Psychology \& Marketing, 14 (4), 379393.

Muniz, A.M. and O'Guinn, T.C. (2001), Brand community, Journal of Consumer Research, 27 (4), 412-432.

Peterson, R.A. and Wilson, W.R. (1992), Measuring customer satisfaction: Fact and artifact, Journal of the Academy of Marketing Science, 20 (1), 61-71.

Ranaweera, C. and Prabhu, J. (2003), On the relative importance of customer satisfaction and trust as determinants of customer retention and positive word of mouth, Journal of Targeting, Measurement and Analysis for Marketing, 12 (1), 82-90.

Reichheld, F.F. (2003), The one number you need, Harvard Business Review, 81 (December), 46-54.

Ryu, G. and Feick, L. (2007), A penny for your thoughts: Referral reward programs and referral likelihood, Journal of Marketing, 71 (January), 84-94.

Schellekens, G.A.C., Verleigh, P.W.J. and Smidts, A. (2010), Language abstraction in word of mouth, Journal of Consumer Research, 37 (August), 207-223.

Spangenberg, E.R., Sprott, D.E., Grohman, B. and Smith, R.J. (2003), Mass-communicated prediction requests: Practical application and a cognitive dissonance explanation for selfprophecy, Journal of Marketing, 67 (July), 47-62.

Spencer, S.J., Zanna, M.P. and Fong, G.T. (2005), Establishing a causal chain: Why experiments are often more effective than mediational analyses in examining psychological processes, Journal of Personality and Social Psychology, 89 (6), 845-851.

Sprott, D.E., Spangenberg, E.R., Block, L.G., Fitzsimons, G.J., Morwitz, V.G. and Williams, P. (2006), The question-behavior effect: What we know and where we go from here, Social Influence, 1 (2), 128-137. 
Sweeney, J.C. and Soutar, G.N. (2001), Consumer perceived value: the development of a multiple item scale, Journal of Retailing, 77 (2), 203-220.

Sweeney, J.C., Soutar, G.N. and Mazzarol, T. (2012), Word of mouth: Measuring the power of individual messages, European Journal of Marketing, 46 (1/2), 237-257.

Sweeney, J., Soutar, G. and Mazzarol, T. (2014), Factors enhancing word-of-mouth influence: Positive and negative service-related messages, European Journal of Marketing, 48 (1/2), 336-359.

Söderlund, M. and Rosengren, S. (2007), Receiving word-of-mouth from the service customer: An emotion-based effectiveness assessment, Journal of Retailing and Consumer Services, 14 (2), 123-136.

Söderlund, M. (2013), Positive social behaviours and suggestive selling in the same service encounter, Managing Service Quality, 23 (4), 305-320.

Trusov, M., Bucklin, R.E. and Pauwels, K. (2009), Effects of word-of-mouth versus traditional marketing: Findings from an Internet social networking site, Journal of Marketing, 73 (September), 90-102.

Tuk, M.A., Verlegh, P.W.J., Smidts, A. and Wigboldus, D.H.J. (2009), Sales and sincerity: The role of relational framing in word-of-mouth marketing, Journal of Consumer Psychology, 19 (January), 38-47.

Van Vaerenbergh, Y., Lariviere, B. and Vermeir, I. (2012), The impact of process recovery communication on customer satisfaction, repurchase intentions, and word-of-mouth intentions, Journal of Service Research, 15 (3), 262-279.

Verlegh, P.W.J., Ryu, G., Tuk, M.A. and Feick, L. (2013), Receiver responses to reward referrals: The motive inferences framework, Journal of the Academy of Marketing Science, 41 (6), 669-682.

Wendlandt M. and Schrader, U. (2007), Consumer reactance against loyalty programs, Journal of Consumer Marketing, 24 (5), 293-304.

Westbrook, R.A. (1987), Product/consumption-based affective responses and postpurchase processes, Journal of Marketing Research, 24 (3), 258-270.

Wien, A.H. and Olsen, S.O. (2014), Understanding the relationship between individualism and word of mouth: A self-enhancement explanation, Psychology \& Marketing, 31 (6), 416425.

Williams, P., Block, L.G. and Fitzsimons, G.J. (2006), Simply asking questions about health behaviors increases both healthy and unhealthy behaviors, Social Influence, 1 (2), 117-127.

Wirtz, J. and Chew, P. (2002), The effects of incentives, deal proneness, satisfaction and tie strength on word-of-mouth behaviour, International Journal of Service Industry Management, $13(2), 141-162$. 
Xiao, P., Tang, C.S. and Wirtz, J. (2011), Optimizing referral reward programs under impression management considerations, European Journal of Operational Research, 215 (3), 730-739.

Zhao, X, Lynch, J.G. and Chen, Q. (2010), Reconsidering Baron and Kenny: Myths and truths about mediation analysis," Journal of Consumer Research, 37 (2), 197-206. 
Table 1:

Means, standard deviations, and zero-order correlations for the main variables in Study 1
M S.D.
1.
2.
3.
4.
5.

1. Requests for WOM

$\begin{array}{lll}4.85 & 3.33 & 1.00\end{array}$

2. WOM behaviour

$2.21 \quad 2.64 \quad 0.19 * * \quad 1.00$

3. WOM intentions

$\begin{array}{ll}7.49 & 2.37\end{array}$

$0.24 * * * \quad 0.37 * * *$

1.00

4. Satisfaction with the advisor

$8.87 \quad 1.31$

0.07

$0.22 * * * \quad 0.48 * * * \quad 1.00$

5. Overall satisfaction

$8.12 \quad 1.62$

$0.29 * *$

$0.58 * * * \quad 0.67 * * *$

1.00

$* * * p<.01, * * p<.05, * \mathrm{p}<.10$ 